\title{
Organizational Role Stress and Work Engagement Among Nurses in a Selected Hospital in Cairo
}

\author{
Abeer Mohamed Seada \\ Department of Nursing Administration, Faculty of Nursing, Cairo University, Egypt, Cairo \\ Email address: \\ abeerseada@yahoo.com \\ To cite this article: \\ Abeer Mohamed Seada. Organizational Role Stress and Work Engagement Among Nurses in a Selected Hospital in Cairo. American Journal \\ of Nursing Science. Vol. 6, No. 1, 2017, pp. 53-62. doi: 10.11648/j.ajns.20170601.17
}

Received: December 21, 2016; Accepted: January 3, 2017; Published: January 28, 2017

\begin{abstract}
Health care professionals, with particular regard to nurses, are exposed to several role stressors and demands of workplace that can adversely decrease their work engagement. Work engagement is perceived to inversely correlate with organizational role stress (ORS). The study aimed to investigate the relationship between organizational role stress and work engagement among nurses. A correlational comparative design was utilized in this study. The present study was conducted in all medical units and all surgical units with its specialties at New Kasr El Aini Teaching Hospital. The study sample composed of a convenience sample of both head nurses/charge nurses and staff nurses working in the previous selected departments. It composed of 52 head nurses/charge nurses out of 66 and 140 staff nurses out of a total of 230. Data of the present study were collected through utilizing the following two tools: The Utrecht Work Engagement Scale (UWES) and Organizational role stress-scale" (ORS). Findings of the present study concluded that that there was no statistical significant correlation between total organizational role stress (ORS) and total work engagement, while only significant correlation was found between total work engagement and the following ORS subscales: Inter role distance, role expectation conflict, role over load, role isolation, personal inadequacy and role ambiguity. A statistical significant difference between head nurses and staff nurses mean scores in relation to their levels of organizational role stressors as well as work engagement. The findings of this study can assist hospitals administrators and policy makers to create an attractive working climate in an effort to decrease levels of organizational role stress among nursing staff and increase their engagement. Replication of the present study on various clinical setting and different health care sectors in Egypt would also be worthwhile.
\end{abstract}

Keywords: Organizational Roles, Roles Stress, Work Engagement, Nurses

\section{Introduction}

Today health care organizations are characterized by rapid change, industrialization, urbanization, as well as technological advancements that lead to rising stress. Most importantly, stress level is on the climb because of the everincreasing competition and attempts at trying to keep pace with advancement in one's field together with the constant threat of falling short of one's own and those of other's expectations [1]. As organizations become more complex, there is a potential for stress increases. Stress is a consequence of socio-economic complexity and to some extent is a stimulant as well. Therefore, one should find ways of using stress productively, and reduce dysfunctional stress [2]. Work stress is intrinsic to nursing. It negatively affects nurses' health and well-being. Nurses, who are under stress, often have job dissatisfaction, increased intention to leave their jobs, burn out, and physical complaints.

The role assigned to an individual within the overall structure of the organization that integrates him with the organization is an important aspect of organization, At workplace, stress related to the role performed by the employee in the organization is one of the important determinants of successful adjustment and subsequent performance of an employee. Stress induced due to roles performed by employees has been considered as a potent organizational stressor [1].

Organization can be seen as a network of roles and stress that arises as a result of occupying a role is known as 'Role Stress' which is experienced by the persons because of their roles they play in the organization pertaining to jobs [3]. [4] stated that role stress is refers to the conflict and tension 
caused by the roles being enacted by a person at any given point of time. Matching of knowledge and skills with the role is an important decision to be made by the role givers in order to accomplish role occupants and organizational goals and at the same time providing them with the job satisfaction or it will affect the performance, productivity and profits of the organization. [1].

It is important to understand that an organization is a super-system of roles and role in itself is a system. A role occupant encounters the following two role systems in an organization. The first is the role space which refers to all the roles performed by an individual as follows: inter role distance, role stagnation, and self-role distance. The second role system is role set and it includes all the roles with whom a role occupant is required to interact for the performance of his role. It includes: role expectation conflict, role erosion, role overload, role isolation, personal inadequacy, role ambiguity, and resource inadequacy. [5, 6, 1, 3, 7 and 8]

Healthcare professionals, particularly nurses are exposed to several job stressors that can adversely affect both their physical and mental health and also reduce work engagement. Work engagement can be seen as the positive opposite of burnout, and it is characterized by energy, involvement and professional efficacy [9]. Moreover [10] state that employees see engagement as a means of repayment toward the organization and as a constructive indicator of commitment. Thus, nurses can choose on what level or to what degree they want to be engaged in their work, which, in turn, influences their loyalty and commitment to the organization.

Engagement is "a positive, satisfying, work-related state of mind characterized by vigor, dedication and absorption."vigour is described as having high levels of work commitment and energy, evenwhen encountering challenges. Dedication is the individuals' sense of importance, impassioned expression, inspiration, and pride at work. Absorption is defined as an absolute focus that one finds difficulty discontinue form work [11]. This construct has shown considerable promise in helping to understand how we might accomplish positive organizational outcomes such as job satisfaction, increased productivity, proactive behaviors, and organizational commitment [12, 13, 14, and 15].

[16] reported that job demands which refers to aspects of the job that need physical or mental effort could have a negative impact on work engagement. While job resources that includes aspects of the job that can help accomplish work goals, reduce job demands or stimulate personal growth may moderate or support this connection. More over [17] stated that when the organization provides adequate job resources, employees' engagement is increases, while when job demands increase, burnout increases. Moreover [18] reported that work life experiences as rewards, and recognition were found to predict vigor, dedication, and absorption.

[19] stated that engaged employees are loyal and psychologically committed to the organization. Therefore, a higher level of work engagement benefits the employer in that it has an impact on the competitive advantage of the organization [20]. While the disengaged employees tend to distance themselves from their work roles and to withdraw from the current work situation. [21] Therefore, work engagement is an important factor within any organization, and more specifically within occupations such as nursing [22and 23] especially since these employees interact with various social systems within the organization and show the lowest level of work engagement [24]

Some researchers agree that work engagement not only help in the decrease of perceived levels of occupational stress [25], but also brings about organizational and financial success through an increase in employee motivation and organizational commitment [21] Therefore, the key focus of this study is to investigate the relationship between organizational role stress and work engagement among nurses.

\section{Significance:}

Stress is not a new issue. However, in recent years it has become more apparent. Nurses are exposed to a wide range of job stressors that may create dissatisfaction, leading to absenteeism and intention to discontinue their job [26]. Role stressors can influence the perceived well-being, job satisfaction, and overall satisfaction, thus affecting their efficiency and skill. It reduces the feeling of well-being and makes one derive less pleasure from work. Organizational role stress is significantly but negatively correlated with personal adjustment and social relations [4]. Research shows that employees' engagement with their work is an important predictor of job satisfaction and intentions to remain in the organization. More over work engagement is perceived to inversely correlate with job stress and other negative job outcomes. Creating conditions that promote employee engagement has the potential to positively influence their retention and improve the patient care. Nevertheless, little is known about the interrelationship between organizational role stress and work engagement in the nursing population with a large gaps in the literature regarding the phenomena of interest [26]. So this research study is an attempt to investigate the relationship between organizational role stress and work engagement among nurses.

Theoretical framework:

\section{Job Demands-Resources model (JD-R model)}

The relationship between stress and engagement can best be seen through the JD-R model of engagement, [26 and 28]. This model holds that the work environment is divided into multiple components of job demands and resources. The job demands which are the primary predictors of negative job strain includes physical, psychological, social, or organizational features of a job that require physical and/or psychological effort from an employee, and are consequently related to physiological and or psychological costs (i.e., strain). While the job resources are the strongest predictors of work engagement and it refers to physical, psychological, social, or organizational features of the job that are functional in achieving work goals, reducing job demands and the physical and/or psychological costs associated with them, and stimulate personal growth and development. Using this model, two assumptions were drawn. The first stated that job 
resources, such as support, feedback, and autonomy, create a motivating process that leads to engagement and productivity. While the second assumption is that the job resources gain more potential for motivation when an employee is confronted with higher job demands.

\section{Methodology}

\subsection{Research Aim and Questions}

The present study aimed to investigate the relationship between organizational role stress and work engagement among first line nurse manager and staff nurses. The following research questions guide the research study:

1 -What is the level of organizational role stressor from the perspective of both first line nurse managers and staff nurses?

2-What perception do first line nurse managers and staff nurses have regarding levels of work engagement?

3-Is there a difference in the perception of both first line nurse manager and staff nurse regarding organizational role stress and work engagement?

4-What is the relationship between organizational role stress and work engagement?

\subsection{Research Design}

Correllational comparative design was utilized. The study follow cross sectional design to investigate the relationship between organizational role stress and work engagement among first line nurse managers and staff nurses.

\subsection{Setting}

The study was conducted in all medical units and all surgical units with its specialties at New Kasr El Aini Teaching Hospital. The total bed capacity of all medical units was 250beds and their specialties include: neuro, kidney, cardiology and blood disease. The total bed capacity of all surgical units was 362 beds and their specialties include: neurology, orthopedic, obstetric, cardiothoracic, and urology.

\subsection{Sample}

The study sample composed of a convenience sample of both head nurses/charge nurses and staff nurses working in the previous selected departments. It composed of 52 head nurses/charge nurses out of a total of 66 and140 staff nurses out of a total of 230. The study sample includes both male and female nurses who are available at time of data collection and who accepted to participate in the study.

\subsection{Tools}

Data for the present study was collected through utilizing the following tools:

\subsubsection{Personal Data Sheet}

It was developed by the researcher and it composed of the following items: age, sex, unit, marital status, position / rank, educational level, years of experiences in nursing, and employment status.

\subsubsection{The Utrecht Work Engagement Scale (UWES)}

The scale was developed by [29] and utilized to measure work engagement among nurses. It includes 17 items which divided into three sub-scales: vigour (6 items), dedication (5 items) and absorption (6 items). The scoring system is measured on a 3-pointlikart scale: 1 (disagree), 2 (neutral) and 3 (agree).

\subsubsection{Organizational Role Stress-Scale (ORS)}

The ORS scale was developed by [30] and it used to measure ten role stressors among nurses. It includes the following ten role stressors as follows:

(1) Inter role distance (IRD): conflict between the organizational and personal roles.

(2) Role stagnation (RS): A feeling of stagnation and lack of growth in the job.

(3) Role expectation conflict (REC): conflicting demands on one by others in the organization.

(4) Role erosion (RE): A decrease in one's level of responsibility.

(5) Role overloads (RO): Too many responsibilities to do everything well.

(6) Role isolation (RI): Feeling of isolation from channels of communication.

(7) Personal inadequacy (PI): lack of knowledge, skills or adequate preparation to be effective in a particular role. (8) Selfrole distance (SRD): A conflict between one's personal values or interests and one's job requirements. (9) Role ambiguity (RA): Unclear feedback from others about one's responsibilities and performance and (10) Resource inadequacy (RIn): nonavailability of resources needed for effective role performance.

The scale holds five items for each role stress i.e. a total of 50 statements. Each statement is scored as 1, 2, 3, 4 and 5, depending on how frequently the respondent feels the way expressed in the statement. The 1 on the scale indicated "never", 2 "occasionally", 3 "sometimes", 4 "frequently", and 5 "always". The total score on each role stress ranges from 5 to 25 and the total ORS score from 50 to 250 . The ratings of five items are totalled to get the total score for each role stressor. Score up to 5 is categorized as low stress, 6-10 is moderate, 11-15 is high and 16-20 is very high.

\subsection{Tools Validity and Reliability}

The two tools contents were developed and tested for its content validity through three expertise from nursing administration departmentat faculty of nursing, Cairo University. Based on their recommendations the necessary modifications were made. Double translation EnglishArabic-English was done to ensure validity of translation. Reliability test was estimated using Cronbach's Alpha Coefficient for the two questionnaires which indicate that both questionnaires were highly reliable. It was 0.94 for work engagement, and 0.89 for ORS. 


\subsection{The Pilot Study}

A pilot study was carried out on a sample of $10 \%$ (from both head nurses/charge nurses and staff nurses) before starting the actual data collection to ascertain the clarity, and applicability of the study tools. It also helped to estimate the time needed to fill in the questionnaire. Based on the results of the pilot study, modifications and rearrangement of some questions were done.

\subsection{Ethical Consideration}

An official permission was obtained from hospital's director and nursing directors of the previous selected hospital to conduct the study at the selected units. They were assured that the data is confidential and used only for research purposes.

\subsection{Procedure}

Once permission was granted from the nursing administrator of the selected hospital to proceed with the prepared research, the purpose and nature of the study was explained to study sample who accept to participate in the study. The respondents were assured for complete confidentiality. An explanation of the instrument was done before it handed to the studied sample on their work places in both morning and afternoon shifts. Sheets were filled out at range of 30 minutes. Data collection activities consumed two months from August to September 2016.

\subsection{Statistical Design}

Data entry and statistical analysis were done using Statistical Package for Social Science (SPSS), version 16.0. The following descriptive statistics were used: frequencies, arithmetic mean: as average describing the central tendency of observations. The standard deviation: as a measure for scattering for outcomes around the mean (for quantitative variables). Independent $t$ test was used to investigate difference in the perception of both first line nurse manager and staff nurse regarding organizational role stress and work engagement. Correlation between variables was evaluated using Pearson's correlation coefficient. Significance was adopted at $\mathrm{p}<0.05$ for interpretation of results of tests of significance.

\section{Results}

Table 1. Frequency and Percentage Distribution of Nurses according to their Demographic Variables $(N=192)$.

\begin{tabular}{lll}
\hline Personal Data & Frequency $(\mathbf{N})$ & $\%$ \\
\hline Age (Years) & & \\
1. 20-less than 25 & 58 & $30.2 \%$ \\
2. 25-less than 30 & 45 & $23.4 \%$ \\
3. 30-less than 35 & 37 & $19.3 \%$ \\
4. 35-less than 40 & 15 & $7.8 \%$ \\
5. 40 years and more & 37 & $19.3 \%$ \\
Mean \pm SD2.625 1.470 & & \\
Educational level & & \\
1. Bacculerate in nursing & 23 & $12.0 \%$ \\
2. Nursing diploma & 157 & $81.8 \%$ \\
3. Others & 12 & $6.2 . \%$ \\
Experience (Year) & & \\
1. Less than 5 yrs & 79 & $41.1 \%$ \\
2. 5-less than 10 & 27 & $14.1 \%$ \\
3. 10 years and more & 86 & $44.8 \%$ \\
Mean \pm SD 2.036 \pm .928 & & \\
Unit: & & \\
1-Medical & 105 & \\
2-Surgical & & \\
Employment: & & \\
1-Full time & & \\
2-Part time & & \\
\hline & & \\
\hline
\end{tabular}

The above table depicts the frequency and percentage distribution of nurses according to their demographic variables. With regard to the age $(30.2 \%)$ were in the age group ranged between 20 to less than 25 . (81.8\%) were nursing diploma. Regarding to years of experiences, the same table shows that $44.8 \%$ of study sample had 10 years of experiences and more. The same table illustrates that $54.7 \%$ of study sample were working in medical department and all study sample (100\%) were full time nurses.

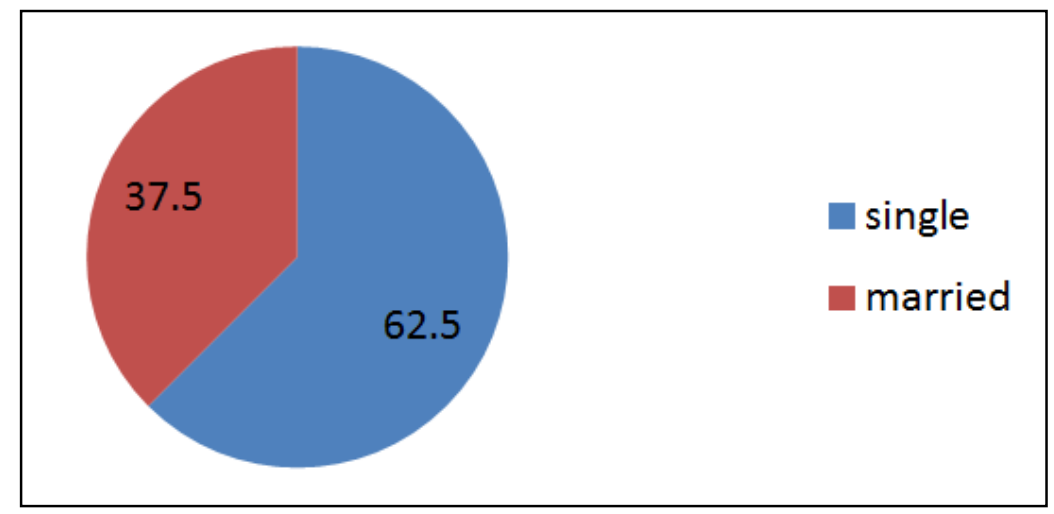

Figure 1. Distribution of Study Sample according to their Marital Status. 
Figure (1) shows that $62.5 \%$ of study sample were single

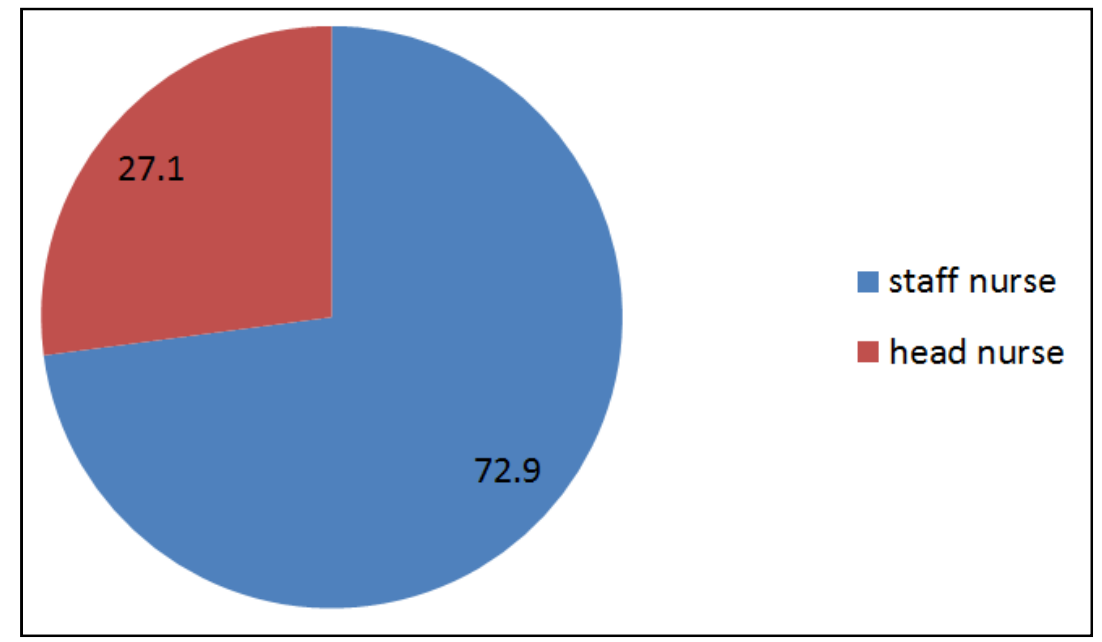

Figure 2. Distribution of Study Sample according to their position / rank.

Figure (2) shows that the highest percentage (72.9\%) of study sample were staff nurses

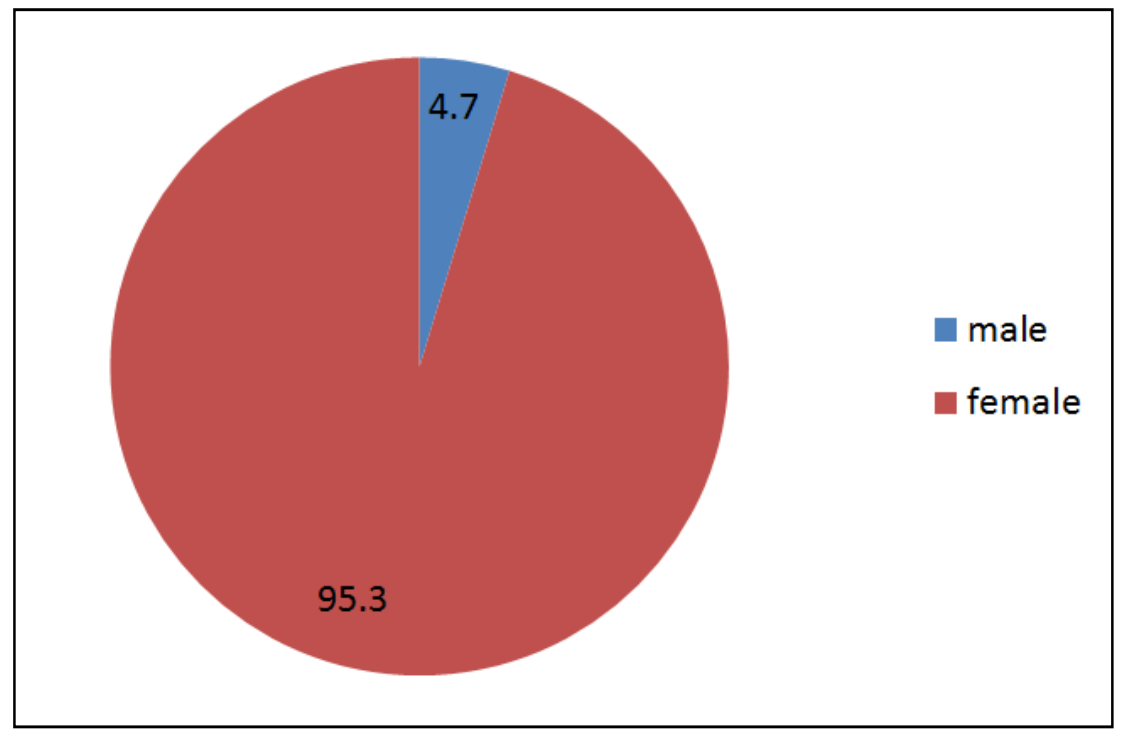

Figure 3. Distribution of Study Sample according to Gender.

Figure (3) represents that the majority of study sample $(95.3 \%)$ were female

Table 2. Comparison between Head Nurses and staff Nurses Mean Scores in relation to level of Organizational Role Stressors (no 192).

\begin{tabular}{|c|c|c|c|c|c|c|}
\hline \multirow{2}{*}{ ORS subscales } & \multicolumn{2}{|c|}{ Head Nurses (No 52) } & \multicolumn{2}{|c|}{ Staff Nurses (No 140) } & \multirow{2}{*}{$\mathbf{T}$} & \multirow{2}{*}{$\mathbf{P}$} \\
\hline & mean & SD & mean & SD & & \\
\hline 1-Inter role distance (IRD) & 15.019 & 4.345 & 16.257 & 4.616 & 1.677 & 0.088 \\
\hline 2-Role stagnation (RS) & 13.634 & 2.178 & 16.164 & 1.817 & 8.108 & $.000 *$ \\
\hline 3-Role expectation conflict (REC) & 17.346 & 3.994 & 17.742 & 4.37 & 0.572 & 0.553 \\
\hline 4-Role erosion (RE) & 10.576 & 2.46 & 15.871 & 5.514 & 6.672 & $.000^{*}$ \\
\hline 5-Role overloads (RO) & 18.826 & 3.2036 & 18.685 & 3.582 & 0.25 & 0.793 \\
\hline 6-Role isolation (RI) & 9.98 & 2.754 & 15.614 & 4.865 & 7.884 & $.000 *$ \\
\hline 7-Personal inadequacy (PI) & 6.73 & 1.951 & 13.364 & 3.32 & 13.55 & $.000 *$ \\
\hline 8-Self-role distance (SRD) & 11.326 & 3.468 & 15.271 & 2.794 & 8.122 & $.000 *$ \\
\hline 9-Role ambiguity (RA) & 9.692 & 2.66 & 15.157 & 4.229 & 8.692 & $.000 *$ \\
\hline 10-Resource inadequacy (RIn) & 19.442 & 1.851 & 18.65 & 2.866 & -1.853 & $.03 *$ \\
\hline total ORS & 132.571 & 14.632 & 162.775 & 30.012 & 6.948 & $.000 *$ \\
\hline
\end{tabular}




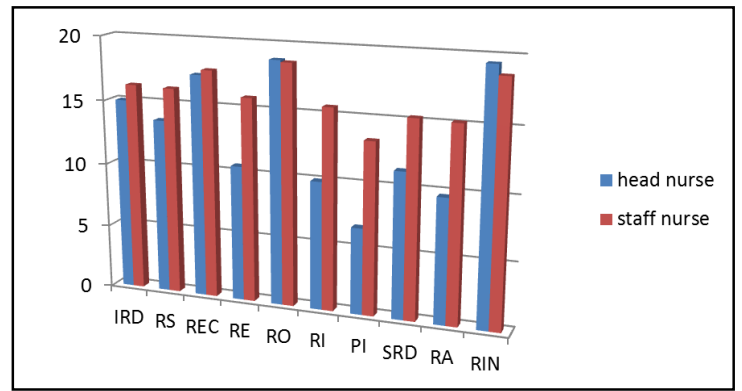

Figure 4. Head Nurses and staff Nurses Mean Scores in relation to their level of Organizational Role Stressors.
Table (2) and figure (4) illustrates that there was a statistical significant differences between head nurses and staff nurses mean scores in relation to their levels of organizational role stressors, as it is clear that staff nurses had highest mean scores of organizational role stressors compared to head nurses in the following subscales: role stagnation, role erosion, role isolation, personal inadequacy, self-role distance, role ambiguity and resource inadequacy which is reflected in total mean scores respectively. (staff nurses mean \pm SD $(162.775 \pm 30.012$, ) and head nurses mean $\pm \mathrm{SD}(132.571 \pm 4.632), \mathrm{P}=.000 *)$

Table 3. Level of Organizational Role Stressors among Study Sample (No 192).

\begin{tabular}{|c|c|c|c|c|c|c|}
\hline \multirow{2}{*}{ ORS subscales } & \multicolumn{3}{|c|}{ Head Nurses (52) } & \multicolumn{3}{|c|}{ Staff Nurses (140) } \\
\hline & Mean & SD & level & Mean & SD & level \\
\hline 1-Inter role distance (IRD) & 15.019 & 4.345 & high & 16.257 & 4.616 & very high \\
\hline 2-Role stagnation (RS) & 13.634 & 2.178 & high & 16.164 & 1.817 & very high \\
\hline 3-Role expectation conflict (REC) & 17.346 & 3.994 & very high & 17.742 & 4.370 & very high \\
\hline 4-Role erosion (RE) & 10.576 & 2.460 & moderate & 15.871 & 5.514 & high \\
\hline 5-Role overloads (RO) & 18.826 & 3.2036 & very high & 18.685 & 3.582 & very high \\
\hline 6-Role isolation (RI) & 9.980 & 2.754 & moderate & 15.614 & 4.865 & very high \\
\hline 7-Personal inadequacy (PI) & 6.730 & 1.951 & moderate & 13.364 & 3.320 & high \\
\hline 8-Self-role distance (SRD) & 11.326 & 3.468 & high & 15.271 & 2.794 & high \\
\hline 9-Role ambiguity (RA) & 9.692 & 2.660 & moderate & 15.157 & 4.229 & high \\
\hline 10-Resource inadequacy (RIn) & 19.442 & 1.851 & very high & 18.650 & 2.866 & very high \\
\hline
\end{tabular}

Note: Score up to 5: low stress, $6-10$ is moderate, $11-15$ is high and $16-20$ is very high.

Table (3) shows the level of organizational role stressors among study sample, according to scoring system of ORS, it is clear from this table that both head nurses and staff nurses had very high level of organizational role stressors, in the following subscales: Role expectation conflict, $(\mathrm{X}=17.346$, $\mathrm{SD}=3.994, \quad \mathrm{X}=17.742, \quad \mathrm{SD}=4.370) \quad$ Role overloads $(\mathrm{X}=18.826, \mathrm{SD}=3.2036, \mathrm{X}=18.685, \mathrm{SD}=3.582)$, and
Resource inadequacy $(\mathrm{X}=19.442, \mathrm{SD}=1.851, \mathrm{X}=18.650$, $\mathrm{SD}=2.866$ ). While data in the same table illustrates that staff nurses had high level of organizational role stressors compared to head nurses who scored moderate level in the following subscales: role erosion, role isolation, personal inadequacy and role ambiguity.

Table 4. Comparison between Head Nurses and Staff Nurses Mean Scores in relation to their level ofWork Engagement (no 192).

\begin{tabular}{|c|c|c|c|c|c|c|c|c|}
\hline \multirow{2}{*}{ Work Engagement Subscales } & \multicolumn{3}{|c|}{ Head Nurses (52) } & \multicolumn{3}{|c|}{ Staff Nurses (140) } & \multirow[t]{2}{*}{$\mathbf{T}$} & \multirow[t]{2}{*}{$\mathbf{P}$} \\
\hline & Mean & SD & mean \% & Mean & SD & mean \% & & \\
\hline 1-Vigour & 10.480 & 2.675 & $58.22 \%$ & 11.607 & 2.138 & $64.48 \%$ & 3.023 & $.01 *$ \\
\hline 2-Dedication & 12.788 & 1.913 & $85.25 \%$ & 11.914 & 2.113 & $79.42 \%$ & -2.611 & $.02 *$ \\
\hline 3-Absorption & 12.019 & 3.363 & $66.77 \%$ & 14.314 & 2.677 & $79.52 \%$ & 4.911 & $.000 *$ \\
\hline total work engagement & 35.28 & 4.749 & $69.17 \%$ & 37.83 & 4.506 & $74.17 \%$ & 3.430 & .001 \\
\hline
\end{tabular}

Data in table (4) illustrates that there was a statistical significant differences between head nurses and staff nurses mean scores in all subscales of work engagement (vigour, dedication and absorption) which is reflected in total mean score respectively. As it is clear that staff nurses had highest mean scores of total work engagement $(\mathrm{X}=37.83$, $\mathrm{SD}=4.506)$ which representing $74.17 \%$ of maximum score than head nurses $(X=35.28, \mathrm{SD}=4.749)$, which representing $69.17 \%$ of maximum score. $\left(\mathrm{T}=3.430, \mathrm{P}=001^{*}\right)$.

Table 5. Correlation between Organizational Role Stressors Subscales and total Work Engagement (total 192).

\begin{tabular}{lll}
\hline \multirow{2}{*}{ ORS Subscales } & \multicolumn{2}{c}{ Work Engagement } \\
\cline { 2 - 3 } & $\mathbf{r}$ & $\mathbf{p}$ \\
\hline 1-Inter role distance (IRD) & .153 & $.034^{*}$ \\
2-Role stagnation (RS) & -.033 & .652 \\
\hline
\end{tabular}

\begin{tabular}{lll}
\hline \multirow{2}{*}{ ORS Subscales } & \multicolumn{2}{l}{ Work Engagement } \\
\cline { 2 - 3 } & $\mathbf{r}$ & $\mathbf{p}$ \\
\hline 3-Role expectation conflict (REC) & -.220 & $.002^{*}$ \\
4-Role erosion (RE) & -.113 & .120 \\
5-Role overloads (RO) & -.227 & $.002^{*}$ \\
6-Role isolation (RI) & -.170 & $.013^{*}$ \\
7-Personal inadequacy (PI) & -.160 & $.004^{*}$ \\
8-Self-role distance (SRD) & -.064 & .381 \\
9-Role ambiguity (RA) & .152 & $.035^{*}$ \\
10-Resource inadequacy (RIn) & -.003 & .962 \\
total ORS & .010 & .0895 \\
\hline
\end{tabular}

* Correlation is significant at the 0.05 level (2-tailed).

** Correlation is significant at the 0.01 level (2-tailed).

It is clear from table (5) that there was no statistical significant correlation between total ORS and total work engagement $(\mathrm{r}=.010, \mathrm{p} .0895)$ While only significant 
correlation was found between work engagement and the following organizational role stressors subscales (inter role distance $\left(\mathrm{r}=153, \mathrm{P} .034^{*}\right)$, role expectation conflict, $(\mathrm{r}=-.220$, $\mathrm{p}=.002 *)$, role over load $(\mathrm{r}=-227, \mathrm{p}=.002 *)$, role isolation $(\mathrm{r}=$ $\left.-.170, \mathrm{p}=.013^{*}\right)$, personal inadequacy $\left(\mathrm{r}=-.160, \mathrm{p}=.004^{*}\right)$ and role ambiguity $\left(\mathrm{r}=.152, \mathrm{p}=.035^{*}\right)$

Table 6. Differences between Study Sample Sex, Marital status, position and both Study Variables. (No 192).

\begin{tabular}{lllll}
\hline \multirow{2}{*}{ Demographic data } & \multicolumn{2}{l}{ total work engagement } & \multicolumn{2}{l}{ total ORS } \\
\cline { 2 - 5 } & $\mathbf{T}$ & $\mathbf{p}$ & $\mathbf{T}$ & $\mathbf{p}$ \\
\hline 1-Sex & 0.028 & 0.701 & -0.04 & 0.58 \\
2-Marital status & -0.134 & 0.063 & -0.283 & $.000^{*}$ \\
3-Position /rank & -0.241 & $.001 *$ & -0.45 & $.000^{*}$ \\
\hline
\end{tabular}

Table (6) shows the differences between study sample sex, marital status, position / rank and total Study variables. It is clear that there was a statistical significant differences between total ORS and both marital status $(\mathrm{t}=-.283$, $\left.\mathrm{p}=.000^{*}\right)$, and position $\left(\mathrm{t}=-.450, \mathrm{p}=.000^{*},\right)$. Also the same table illustrates a statistical significant differences between work engagement and only study sample position (-.241, p $=.001 *)$. While no statistical significant differences was found between both study variables and sex.

Table 7. Correlation between Study Sample Age, Years of Experience, Educational Level and both study Variables (No 192).

\begin{tabular}{lllll}
\hline \multirow{2}{*}{ Demographic data } & \multicolumn{2}{c}{ total work engagement } & \multicolumn{2}{c}{ total ORS } \\
\cline { 2 - 5 } & $\mathbf{r}$ & $\mathbf{p}$ & $\mathbf{r}$ & $\mathbf{p}$ \\
\hline 1-Age & -.292 & $.000^{*}$ & -.504 & $.000^{*}$ \\
2- Years of experience & -.108 & .136 & -.717 & $.000^{*}$ \\
3- Educational level & .091 & .210 & .215 & $.003^{*}$ \\
\hline
\end{tabular}

It is clear from the above table (7) that there was a statistical significant correlation between total ORS and study sample age $\left(r=-.504, p=.000^{*}\right)$, years of experience $(r=$ $-.717, \mathrm{p}=.000^{*}$, )as well as educational level $(\mathrm{r}=215$. $\mathrm{p}=.003 *)$. While a statistical significant correlation was found between total work engagement and only age $(\mathrm{r}=$ $\left..292, \mathrm{p}=.000^{*}\right)$.

\section{Discussion}

Nurses are exposed to a wide range of organizational role stressors that may create dissatisfaction, leading to absentessism and intention to discontinue their jobs. Work engagement plays an important role in driving the organization's goals and is instrumental in supporting and promoting a healthy work environment. [26]. This study aimed to investigate the relationship between organizational role stress and work engagement among first line nurse manager and staff nurses.

Findings of the present study revealed that there was a statistical significant differences between head nurses and staff nurses mean scores in relation to level of organizational role stressors (ORS). More over when comparing between nursing position or rank as one of demographic variable and ORS it was revealed that there was a statistical significant differences between total ORS and nurses positions. As it is clear that staff nurses had highest mean scores and high level of organizational role stressors compared to head nurses who scored moderate level in the following subscales:, role erosion, role isolation, personal inadequacy, self-role distance, and role ambiguity. Findings of the present study is contrary to study done by [31] who reported that nurse managers scored significantly higher on job role stressors compared with other groups of nurses. While [32] founded that there is no variation in job-related stress due to position or ranking of nurses. In addition [8] added that hospital managers had organizational role stress at moderate to high levels.

From the researcher point of view this might be contributed to the variation in the structure and nature of job among different nursing ranks or position. As staff nurses level of stress may results from being at a direct contact with patients as they provide direct patient care so they have no chance to adopt new role which lead to role stagnation, also they may feel that their values or worth as nurses decreased when patients harass them which lead to role erosion. More over when staff nurses are over loaded with job duties and responsibilities this might affect on their interaction with their colleagues which give the feeling of being isolated. In addition because of their direct contact with patients they are more liable to experience conflict between their personal values, and beliefs and their roles compared to head nurses who are not in direct contact with patients. Also staff nurses may feel inadequate in their preparation, having inadequate experience and skills compared to their head nurses. All these factors give rise of feeling stressed at work compared to head nurses.

More over, results of the present study revealed that both head nurses and staff nurses had very high level of organizational role stressors, regarding role expectation conflict, role overloads and resource inadequacy. This result is contrary to study done by [7] as they founded their respondents had medium scores regarding role expectation conflict while they scored high regarding inter role distance. In the same issue [33] reported that that all ORS give rise to moderate levels among the employees sampled. From the researcher point of view, regardless of variation in the nature and structure of job both head nurses and staff nurses are more liable to stressors arising from role over load when they feel that they have too many responsibilities or activities expected of them in respect to their available time, and abilities. More over both experience high role-expectation conflict because of the conflicting demands from superiors that may interfere with their social life and make them feel stressed out. In addition inadequate resources in the work place lead to high level of stress among all employees because they want to be effective in their work, perform their job well, as well as having opportunities to learn new skills in the presence of adequate resources.

Another finding in this study revealed that there was a 
statistical significant difference between head nurses and staff nurses total mean scores in relation to their perception of work engagement. As it is clear that staff nurses had highest mean scores of total work engagement compared to head nurses. More over staff nurses had higher mean scores than head nurses regarding both vigour and absorption while head nurses had higher mean scores than staff nurses regarding dedication subscale. In this respect study done in Egypt by [34]revealed that the highest mean score was observed for head nurses' dedication and vigour while the least level of head nurses' was observed for absorption. More recently another study in Egypt done by [35] reported that staff nurses had highest mean percentage of total work engagement. In addition, study done by [36]reported that staff nurses are slightly more dedicated than they are absorbed or have vigour. In the same line study done by [31] reported that the highest percentage of staff nurses experienced high absorption. From the researcher point of view, unexpected result in this study revealed that staff nurses had highest mean scores of work engagement than that of head nurses especially in vigour and absorption subscales although they had highest level of organizational role stress (ORS)compared to that of head nurses. This might be contributed to the distribution of study sample according to their personal characteristics as the highest percentage of study sample were staff nurses, at younger age as well as single. All theses personal factors might lead to felling of vigour and absorption.

One of the major findings in this study was that there was no statistical significant correlation between total ORS and total work engagement. While only significant correlation was found between work engagement and the following ORS subscales: Inter role distance, role expectation conflict, role over load, role isolation, personal inadequacy and role ambiguity. In this respect [37] reported that as work stressors increased, work engagement is lowered. Moreover,[38] reported that role stress was negatively correlated to work engagement, as they added that an employee's engagement level will decrease when presented with increased stress. In addition,[39]reported that as job demands (role stress) goes up, engagement goes down. As job demands exhaust employees' mental and physical resources, leading to the depletion of energy, absorption, and dedication related to engagement [40, 41 and 42]. From the researcher point of view several role stressors may negatively affect on employees engagement. As when employees encountered conflict between their roles and functions at home and at work they tend to experience inter role distance that negatively affect their loyalty, and commitment to organization. Also the conflicting and multiple job demands appear to create pressure on individual which negatively impact on work engagement. In addition when nurses feel that their job provides them with little opportunities for meaningful interaction with their colleges they experience role isolation that affected negatively on their engagement. In addition the tension at work caused by role ambiguity and personal inadequacy make individual worker feel ineffective and inadequate in his or her preparation which in turn might lead to low sense of importance, inspiration, and pride at work.

When comparing between demographic characteristics of study sample and organizational role stressor (ORS). Results of the present study revealed that there was a statistical significant difference between total ORS and marital status. This result is consistence with [7] as they reported in their research study that there was a statistical significant differences between marital status of study sample and the majority of ORS: as inter role distance, role stagnation, role over load, role expectation conflict, and role ambiguity. From the researcher point of view, married nurses compared to single ones are more liable to experience more conflict between their roles and responsibilities at home and at work. Also their job might hinder their relationship with family members. In addition they may experience role over load and role expectation conflict as the demands of their job might interfere with their supervisor's expectation.

Results of this study also revealed a statistical significant correlation between study sample age, years of experiences, educational level and total ORS. This resultis in the same line with [33] as they reported that educational qualifications and work experience have a significant impact on employees' stress levels. In this respect [8] reported that there was no significant difference in the average overall stress levels between the different educational level of study sample while they reported a statistically significant difference between years of experiences and over all ORS. More over [7] found in their research study that there was a statistical significant correlation between some role stressors like role stagnation, role expectation conflict as well as role erosion and study sample age. While [33] states that there is no significant difference in the stress levels of employees of different age groups. Another finding in this study revealed that there was no statistical significant differences between study sample gender and ORS. This result is contrary to [8] as they reported that the perceived stress levels are tend to be higher among women as compared to men due to family responsibilities resulting in work life conflicts.

When comparing between demographic characteristics of study sample and work engagement, it was revealed that there was statistical significant differences between work engagement and study sample age as well as their position/rank. While no statistical significant differences were found between work engagement and other demographic variable such as sex, marital status, years of experiences and educational level. In this respect [36] found no any significant differences between work engagement and nurses demographic characteristics. Also study done in Egypt by [35] revealed no statistical significant differences between work engagement and respondents' sex, age, years of experiences and marital status.

\section{Conclusion}

Findings of the present study concluded that, there was no 
statistical significant correlation between total organizational role stress and total work engagement while only significant correlation was found between total work engagement and the following ORS subscales: Inter role distance, role expectation conflict, role over load, role isolation, personal inadequacy and role ambiguity. A statistical significant difference between head nurses and staff nurses mean scores in relation to their level of organizational role stressors as well as work engagement.

Practical implication and recommendations for hospital:

- The findings of this study can assist hospitals administrators and policy makers to create an attractive working climate in an effort to decrease levels of organizational role stress among nursing staff and increase their engagement.

- Managers of nursing services should consider role stressors and its negative influence on nurse's engagement outcomes in order to improve their performance.

- Strategies to manage organizational work stressors are recommended to promote work engagement among nursing staff. So stress management programs should be encouraged and the organization should dispense information about the fundamentals of stress and its managing tactics like exercise, meditation. Also standard working norms, scientific performance appraisal, and genuine promotion system need to be coherently established..

- Stressors among staff nurses that arise from role erosion and role stagnation can be handled by taking measures for enrichment of roles; analysis and redesign of eroded roles and abolition of roles that cannot be enriched.

- Also to decrease stressors among staff nurses that arise from personal inadequacy, work must be given according to nurses level of experience, skills, knowledge and qualifications so that they can cope easily with the role given to them and provide them with appropriate developmental opportunities. Ensure that staffs are informed of appropriate services, policies and facilities.

- Finally hospital administrators have the responsibility to monitor workloads and working hours to ensure that individual staffs are not overloaded as well as provide adequate resources for nursing staff to enable them to perform their job well as well as learn new skills in the presence of adequate resources.

Implication for nursing research:

The following recommendations resulting from the study can be made for future research:

- $\quad$ Establish the practical use of the engagement concept in nursing and future research to design and evaluate an intervention program that focuses on fostering engagement among nursing staff.

- Replication of the present study on various clinical setting and different health care sectors in Egypt would also be worthwhile.

\section{References}

[1] Dhawan, N. (2013): An Empirical Analysis of Role Stressors in Banking Sector. THE GLOBAL e LEARNING JOURNAL VOLUME 2, NUMBER 2

[2] Ahmady, S., Changiz, T., Masiello, I. Brommels, M. (2007): Organizational role stress among medical school faculty members in Iran: dealing with role conflict. BMC Med Educ. 2007; 7: 14 .

[3] Christiana, B. V. \& Mahalakshmi, V (2013): Role Stress and its Impact on Public and Private Sector Managers in Chennai: An Empirical Study. International Journal of Management \& Business Studies. Vol. 3, Issue 1, ISSN: 2231-2463 (Print) w ww. i jmb s. com

[4] Anand, K. Nagle, Y. K., Misra, N. \& Dang, S. (2013): Influence of Organizational Role Stress on Perceived Burnout among Military Aircrew. International Journal of Scientific and Research Publications, Volume 3, Issue 2, 1 ISSN 22503153.www.ijsrp.org.

[5] Ratna, R. Chawla, S. \& Garg, M (2011): Organizational Role Stress and its Management among IT Professionals. International Conference on Technology and Business Management 28-30, 953

[6] Lu, J. L (2008): Organizational Role Stress Indices Affecting Burnout among Nurses. Journal of International Women's Studies Vol. 9, 3

[7] Kairanna, S \& Suresh, R. (2014): A Study on Organizational Role Stress among Women Working In Private Colleges in Mangalore using ORS scale. IOSR Journal of Humanities And Social Science (IOSR-JHSS) Volume 19, Issue 10, PP 25-28 e-ISSN: 2279-0837, p-ISSN: 2279-0845. www.iosrjournals.org www.iosrjournals.org.

[8] PatwardhanV, Mayya, S\& Joshi, H. G. (2014): Organizational Role Stress among Managers in the Indian Hospitality Industry. International Journal of Business and Management Invention ISSN (Online): 2319 - 8028, ISSN (Print): 2319 801X www.ijbmi.org Volume 3 Issue 9 || September. 2014 || PP. 13-19 www.ijbmi.org 13 | Page

[9] Fiabane E1, Giorgi I, Sguazzin C, Argentero P. (2013): Work engagement and occupational stress in nurses and other healthcare workers: the role of organizational and personal factors. Journal of clinical nurse 22 (17-18): 2614-24. doi: 10.1111/jocn.12084. Epub 2013 Mar 29.

[10] Saks, A. M., \& Rothmann, J. L. (2006). Antecedents and consequences of employee engagement. Journal of Managerial Psychology, $21 \quad$ (7), 600-619. http://dx.doi.org/10.1108/02683940610690169

[11] Freeney, Y., \& Tiernan, J. (2009): Exploration of the Facilitators of and Barriers to Work Engagement in Nursing. International Journal of Nursing Studies, 46, 1557-1565. http://dx.doi.org/10.1016/j.ijnurstu.2009.05.003

[12] Saks, A. M. (2006): Antecedents and consequences of employee engagement. Journal of Managerial Psychology, 21 (7), 600-619.

[13] Salanova, M. \& Schaufeli, W. B. (2008). A cross-national study of work engagement as a mediator between job resources and proactive behavior. The international Journal of Human Resource Management, 19 (1), 116-131. 
[14] Shimazu, A., Schaufeli, W. B., Kosugi, S., Suzuki, A., Nashiwa, H., Kato, A., et al. (2008). Work engagement in Japan: Validation of the Japanese version of the Utrecht Work Engagement Scale. Applied Psychology: An International Review, 57 (3), 510-523

[15] Wefald, A. J. \& Downey, R. G. (2009). Construct Dimensionality of engagement and its relation with satisfaction. The Journal of Psychology, 143 (1), 91-111.

[16] Wright, J. (2009): ROLE STRESSORS, COWORKER SUPPORT, AND WORK ENGAGEMENT: A LONGITUDINAL STUDY. Published master thesis. The Faculty of the Department of Psychology San José State University.

[17] Hakanen, J. J., Bakker, A. B., \& Schaufeli, W. B. (2006). Burnout and work engagement among teachers. Journal of School Psychology, 43, 495-513.

[18] Caponetti, A. R. (2012): The Correlates of Work Role Stress with Employee Burnout, Engagement. PhD diss., University of Tennessee, http://trace.tennessee.edu/utk_graddiss/1407

[19] Jordaan, G. M. E., \& Rothmann, S. (2005). Work engagement of academic staff in South African higher institutions. Potchefstroom, South Africa: WorkWell Research Unit for People, Policy and Performance, North-West University. PMCid: PMC1831920.

[20] Beukes, I. and Botha, E. (2013): Organizational commitment, work engagement and meaning of work of nursing staff in hospitals. SA Journal of Industrial Psychology/SA Tydskrifvir Bedryfsielkunde, 39 (2),

[21] Koyuncu, M., Burke, R. J., \& Fiksenbaum, L. (2006). Work engagement among women managers and professionals in a Turkish bank: potential antecedents and consequences. Equal Opportunities International, 25, 299-310. http://dx.doi.org/10.1108/02610150610706276

[22] Meyers, C. (2007). Industrial Psychology. New York, NY: Garnsey Press.

[23] Simpson, M. R. (2008). Engagement at work: A review of the literature. International Journal of Nursing Studies, 1, 1-13.

[24] Cooper, C., \& Burke, R. (2008). The Peak Performing Organization. London, UK: Routledge.

[25] Schaufeli, W. B., \& Bakker, A. B. (2004). Job demands, job resources and their relationship with burnout and engagement - A multi-sample study. Journal of Organizational Behavior, 25, 293-315. http://dx.doi.org/10.1002/job.248

[26] ThianJ. H., Kannusamy, P. \& Yobas, P. (2013): Stress, Positive Affectively, and Work Engagement among Nurses. An Integrated Literature Review. Singapore Nursing Journal. $40,(1)$.

[27] Bakker, A. B. \& Demerouti, E. (2007). The job demandsresources model: State of the art. Journal of Managerial Psychology, 22, 309-328.

[28] Demerouti, E., Bakker, A. B., De Jonge, J., Janssen, P. P. M., \& Schaufeli, W. B. (2001) Burnout and engagement at work as a function of demands and control. Scandinavian Journal of Work, Environment and Health, 27, 279-286.,

[29] Bakker, A., Schaufeli, W., and Salanova, M. (2006). The measurement of work engagement with a short questionnaire: A cross- national study. Educational and Psychological Measurement, 66, 701-716. doi: 10.1177/0013164405282471.

[30] Pareek, U. (1983). Role stress scale: ORS scales booklet, answer sheet, and manual. Ahmadabad: Naveen Publications.

[31] Jeanaro, C., Flores, N., Orgaz, M. B., \&Cruz, M. (2011): Vigour and dedication in nursing professionals. Toward better understanding of work engagement. Journal of Advanced Nursing. 67 (4). 865-875

[32] Dagget, T, Molla, A \& Belachew, T. (2016): Job related stress among nurses working in Jimma Zone public hospitals, South West Ethiopia: a cross sectional study. http://creativecommons.org/licenses/by/4.0.

[33] Bano, B \& Jha, R. K. (2012): Organizational Role Stress Among Public and Private Sector Employees: A Comparative Study. The Lahore Journal of Business. Volume (1), no (1). pp. 23-36.

[34] Gaber, H, and El-Shaer, A (2013): Head Nurses ' Job Demands and Resources and its Relationship with Their Work Engagement at Mansoura University Hospitals. Public Policy and Administration Research., 1Vol. 3, No. 4, P: 2224-573.

[35] Abed, F and Elewa, H. A (2016): The Relationship between Organizational Support, Work Engagement and Organizational Citizenship Behavior as Perceived by Staff Nurses at Different Hospitals. Journal of Nursing and Health Science (IOSR-JNHS). Volume 5, Issue 4. PP 113-123.

[36] Awuku, E. N. (2013): Stress, work engagement, and psychological well being of nurses at state hospitals. Windhoek, Rehoboth, Okahandja.. Published master thesis in clinical psychology. University of Namibia. P: 93-96.

[37] Simmons, A. M. (2014): Work Stressors and Perceived Organizational Support on Front Line Nurse Manager Work Engagement. http://hdl.handle.net/10755/335088.

[38] Bakker, A. B., van Veldhoven, M., \& Xanthopoulou, D. (2010). Beyond the demand-control model: Thriving on high job demands and resources. Journal of Personnel Psychology, 9 (1), 3.http://dx.doi.org/10.1027/1866-5888/a000006.

[39] Demerouti, E., \& Bakker, A. B. (2011). The job demandsresources model: Challenges for future research. SA Journal $\begin{array}{llll}\text { of Industrial Psychology, } 37 & \text { (2), 1-9. }\end{array}$ http://dx.doi.org/10.4102/sajip.v37i2.974.

[40] Ramos, A. OAlés, Y. B\& Mendoza-Sierra, I (2014): Role Stress and Work Engagement as Antecedents of Job Satisfaction in Spanish Workers. Journal of Industrial Engineering and Management. JIEM, 2014 - 7 (1): 360-372 http://dx.doi.org/10.3926/jiem.992.

[41] JazreelHui Min Thian, Premarani Kannusamy, Hong-Gu He1, PiyaneeKlainin-Yobas (2015): Relationships among Stress, Positive Affectivity, and Work Engagement among Registered Nurses. Psychology, 6, 159-167. http://dx.doi.org/10.4236/psych.2015.62015.

[42] Montgomery, A., Spânu, F., Băban, A. Panagopoulou, E. (2015): Job demands, burnout, and engagement among nurses: A multi-level analysis of ORCAB data investigating the moderating effect of teamwork. Burnout research. 2 (3) 71-79. 